\title{
RANCANG BANGUN HYBRID COUPLER UNTUK LOW-COST BUTLER MATRIX
}

\author{
Rudy Fernandez \\ Jurusan Teknik Elektro, Fakultas Teknik, Universitas Andalas \\ Corresponding author, e-mail: rfernandez@ft.unand.ac.id
}

\begin{abstract}
Abstrak-Butler Matrix merupakan salah satu jaringan switched beam yang digunakan pada Smart Antenna system. Hybrid coupler merupakan salah satu komponen yang memainkan penting dalam jaringan tersebut. Rancangan coupler dibentuk dengan menggunakan rumus-rumus yang berlaku untuk mendapatkan dimensi awalnya, setelah itu disimulasi untuk memeriksa kinerjanya. Jika hasil simulasi sudah memenuhi persyaratan yang ditentukan, selanjutnya difabrikasi dan diukur dengan Network Analyzer. Coupler ini difabrikasi dengan menggunakan suatu substrate yang relatif murah dan mudah diperoleh dipasaran. Substrate FR4 ini memiliki ketebalan 1,6 mm dengan konstanta dielektrik 4,3. Hasil pengukuran dari rancangan hybrid coupler yang difabrikasi pada frekuensi $2.45 \mathrm{GHz}$ menunjukkan nilai reflection loss $-18,27 \mathrm{~dB} d \mathrm{~dB}$, isolation loss $-19,45 \mathrm{~dB}$ dan beda phase $-94,4^{\circ}$. Hasil yang diperoleh ini menunjukkan kinerja yang relatif dekat dengan hasil simulasi.
\end{abstract}

\section{Kata Kunci : Hybrid Coupler, Return Loss and Phase Coupling}

\begin{abstract}
Butler Matrix is one of switched beam network that used on a Smart Antenna system. Hybrid coupler plays an important role in the network. A proposed coupler is designed by applying the formula to get an initial dimension and then it is simulated by MWO to verify its performance whether meet the specific requirement. The optimized simulated design is fabricated and measured by network analyzer. The coupler uses a substrate which is relatively cheap and easy to find in a market. The substrate FR4 has thickness of $1.6 \mathrm{~mm}$ with dielectric constant of 4.3. The measurement result of the fabricated hybrid coupler in frequency 2.45 GHz, shows that reflection loss $-18,27 \mathrm{~dB}$, isolation loss $-19,45 \mathrm{~dB}$ and phase coupling $-94,4^{\circ}$. The measurement result shows relatively well agreement with the simulation.
\end{abstract}

Keywords : Hybrid Coupler, Return Loss and Phase Coupling

Copyright $\odot 2017$ JNTE. All rights reserved

\section{PENDAHULUAN}

Penyediaan layanan suara dan layanan data kecepatan tinggi oleh suatu operator telekomunikasi bergerak bagi para pelanggan sudah menjadi suatu keharusan. Pada saat bersamaan, operator juga ingin meningkatkan jumlah pelanggan yang dapat dilayani oleh tiap base station agar dapat mengurangi biaya keseluruhan jaringan dan membuat biaya layanan menjadi terjangkau bagi pelanggan. Sehingga sistem nirkabel yang dapat menyediakan kecepatan data yang tinggi dan sekaligus memiliki kapasitas yang besar merupakan suatu kebutuhan mendesak.

Bagi operator yang menggunakan frekuensi populer seperti pada pita Industry, Scientific and Medical (ISM) dimana teradapat banyak penggunanya seperti untuk Wireless Personal Area Networks (WPANs), Wireless Local Area
Networks (WLANs) dan banyak lainnya mengingat ketersediaannya yang cukup luas. Pita frekuensi ISM berada pada rentang 2.4-2.5 GHz. Begitu banyaknya macam-macam peralatan yang menggunakan frekuensi yang sama, menyebabkan munculnya penurunan kinerja secara significant dan interferensi yang cukup tinggi. Smart Antenna System merupakan salah satu solusi untuk mengatasi hal tersebut [1].

Smart Antenna System secara umum dapat dikategorikan atas dua pendekatan berdasarkan cara transmisinya, yaitu adaptive arrays dan switched beams [2]. Teknik adaptive arrays menggunakan elemen antenna yang multiple baik pada sisi pemancar maupun penerima dalam link komunikasi, dimana sinyal - sinyal diproses secara adaptif untuk mengeksploitasi spatial dari kanal radio yang bergerak. Teknik ini memungkinkan untuk mengarahkan main 
lobe dalam arah sinyal yang diinginkan dan membentuk pattern nulls dalam arah interferensi yang muncul, sehingga menghasilkan signal-tonoise ratio (SNR) yang lebih baik. Akan tetapi, implementasi teknik ini sangat kompleks dan menghasilkan sistem yang berbiaya tinggi [2-3].

Jaringan Butler Matrix konvensional pada dasarnya terdiri dari Hybrid Coupler (hybrid junction), phase shifter dan crossover (cross line). Hybrid coupler pada dasarnya adalah suatu perangkat pasif empat port yang memiliki 4 buah lengan yang simetris untuk dapat menghasilkan sinyal output yang berbeda phase $90^{\circ}$ [4]. Jaringan Butler Matrix yang ada saat ini memiliki bentuk yang lebih kompleks [5-6]. Penggunaan 2 buah lapisan substrat diterapkan pada [7] yang menyebabkan biaya pembuatan serta material yang digunakan menjadi relatif mahal. Rancangan jaringan Butler Matrix pada penelitian ini ditentukan oleh konfigurasi coupler yang digunakan serta substratenya, sehingga pada akhirnya diperoleh rancangan yang berbiaya relatif rendah namun tetap memiliki kinerja yang baik.

Hybrid coupler dirancang secara microstrip, dengan keuntungan antara lain; berbiaya rendah, merupakan suatu rangkaian yang lengkap pada suatu substrat dan sangat cocok untuk integrasi rangkaian microwave terpadu. Bentuk konfigurasi yang dimiliki lebih sederhana dibandingkan pada [8-11]. Dengan menggunakan FR4 sebagai substrat yang memiliki harga relatif murah dan mudah dicari dipasaran, akan menghasilkan rancangan yang berbiaya relatif rendah. Substrat ini memiliki ketebalan $1.6 \mathrm{~mm}$ dengan konstanta dielektrik sebesar 4.3.

\section{PERANCANGAN COUPLER}

Bentuk hybrid coupler dirancang sesuai dengan konfigurasi yang ditunjukkan pada Gambar 1. Saluran input pada hybrid coupler terbagi menjadi lengan seri dan lengan shunt. Jarak antar lengan sejauh $1 / 4 \lambda$ dimana saluran inputnya memiliki karakteristik impedansi sebesar $\mathrm{Z}_{0}$, sedangkan impedansi pada lengan series sebesar $Z_{0} / \sqrt{2}$ ohm dan impedansi pada lengan shunt sebesar $\mathrm{Z}_{0}$ ohm.

Adanya 2 impedansi karakteristik yang berbeda pada coupler ini, memberikan lebar saluran yang berbeda pula untuk dihitung. Lebar saluran mikrostrip $(W)$ tergantung dari impedansi karakteristik $\left(Z_{0}\right)$, ketebalan (h) dan konstanta dielektrik $\left(\varepsilon_{\mathrm{r}}\right)$ dari substrat yang digunakan. Proses penghitungan lebar saluran ini menggunakan software TXline 2003. Software ini menerapkan rumus untuk menghitung lebar saluran mikrostrip yang diberikan oleh persamaan di bawah ini [1].

$W=\frac{2 h}{\pi}\left\{B-1-\ln (2 B-1)+\frac{\varepsilon_{r}-1}{2 \varepsilon_{r}}\left[\ln (B-1)+0,39-\frac{0,61}{\varepsilon_{r}}\right]\right\}$

Dengan $\varepsilon_{r}$ adalah konstanta dielektrik relatif dan nilai B ditunjukkan oleh :

$B=\frac{60 \pi^{2}}{Z_{0} \sqrt{\varepsilon_{r}}}$

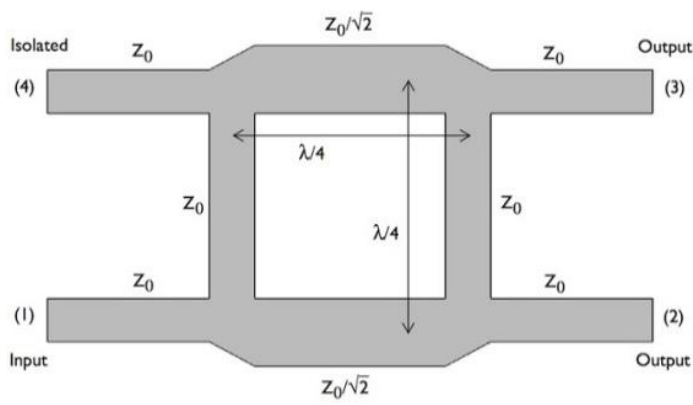

Gambar 1. Bentuk geometris hybrid coupler

Analisis karakterisasi hybrid coupler dilakukan dengan berdasarkan kepada 3 parameter yaitu reflection loss, isolation loss dan phase coupling [4]. Pada Gambar 1, port 1 dan port 4 merupakan input port serta port 2 dan port 3 merupakan output port. Parameter yang diukur antara kedua input port $\left(\mathrm{S}_{14}, \mathrm{~S}_{41}\right)$ dan antara kedua output port $\left(\mathrm{S}_{32}, \mathrm{~S}_{23}\right)$ adalah isolation loss. Sedangkan reflection loss diukur dengan parameter $S_{11}, S_{22}, S_{33}$, dan $S_{44}$. Parameter reflection loss dan isolation loss dipersyaratkan agar bernilai $\leq-10 \mathrm{~dB}$ [12]. Parameter VSWR (voltage standing wave ratio) juga diukur untuk memeriksa perbandingan antara tegangan yg diberikan dengan tegangan yang dipantulkan dengan ketentuan VSWR $\leq 2$. Phase coupling diukur dengan parameter $S_{12}, S_{13}$. Nilai koefisien dari phase coupling harus memiliki magnitude yang sama besar dengan beda phase $90^{\circ}$. Ketiga parameter tersebutlah yang menjadi ukuran kinerja hybrid coupler. 
Berdasarkan Gambar 1 dan rumus (1)(2) maka lebar saluran masing-masing lengan pada normal hybrid coupler dapat dihitung. Pada lengan shunt yang memiliki nilai impedansi Zo $=50 \Omega$, maka lebar salurannya adalah sebesar 3 $\mathrm{mm}$ dan lengan seri yang memiliki nilai impedansi $\mathrm{Zo} / \sqrt{2}=35 \Omega$ maka lebar salurannya akan sebesar $5.25 \mathrm{~mm}$. Dengan hasil tersebut berarti lebar saluran pada lengan seri sama besar dengan jarak antar lengan seri, dimana jarak $1 / 4$ $\lambda$ untuk $2.45 \mathrm{GHz}$ adalah sebesar $30.6 \mathrm{~mm}$.

Dimensi $42 \mathrm{~mm}$ x $42 \mathrm{~mm}$ didapatkan dari hasil perhitungan yang diberikan pada persamaan yang diberikan pada gambar 2 dan formula yang ada. Rancangan dilakukan berdasarkan perhitungan yang diterapkan pada dimensi yang diberikan pada Gambar 1 dan hasil perhitungan yang diperoleh dari penggunaan rumus-rumus, dapat dilihat pada Gambar 2. berikut :

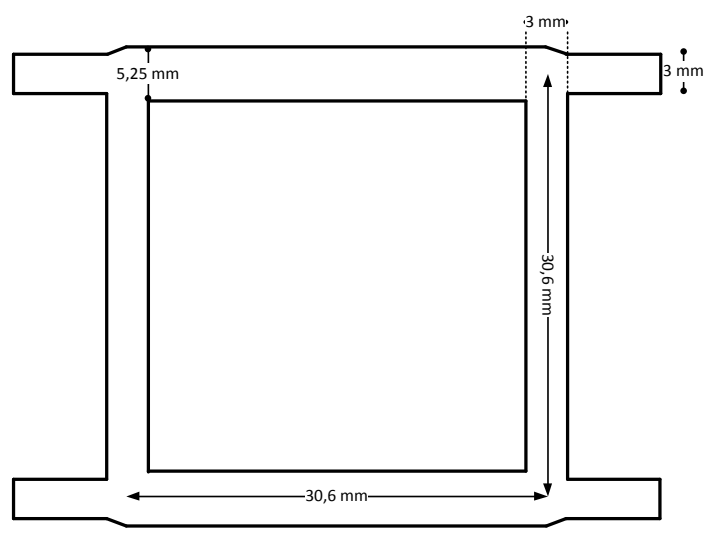

Gambar 2. Bentuk geometris rancangan hybrid coupler

\section{HASIL DAN PEMBAHASAN}

Rancangan pada Gambar 2 ini disimulasikan dengan menggunakan perangkat lunak MWO 2012 (Microwave Office 2012). Proses optimasi perlu dilakukan mengingat rancangan tersebut dibuat berdasarkan hasil perhitungan dari formula yang ditetapkan.. Hasil simulasi menunjukkan bahwa reflection loss $-18,27 \mathrm{~dB}$, isolation loss $-24,04 \mathrm{~dB}$ dan phase coupling 91.33 ${ }^{\circ}$. Nilai-nilai parameter tersebut telah memenuhi kriteria yang ditetapkan sebelumnya.

Rancangan hasil simulasi merupakan dasar untuk di fabrikasi, seperti pada Gambar 3 berikut ini:

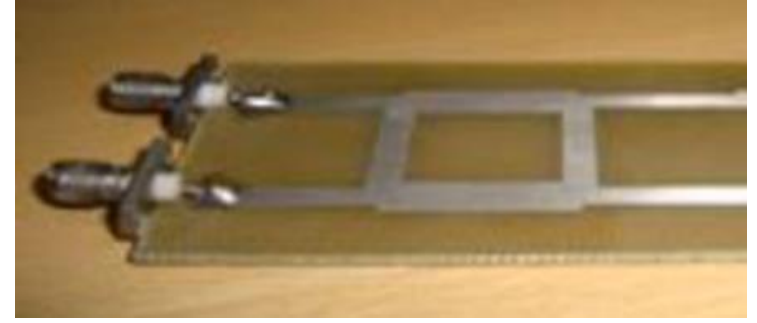

Gambar 3. Hybrid coupler hasil fabrikasi

Lalu hybrid coupler fabrikasi ini diukur dengan Network Analyzer. Dari hasil pengukuran, diperoleh nilai reflection loss, isolation loss dan VSWR. Hasil pengukuran ini dibandingkan dengan nilai parameter hasil simulasinya. Perbandingan antara hasil simulasi dan pengukuran untuk reflection loss dan VSWR diperlihatkan pada Gambar 4 dan 5.

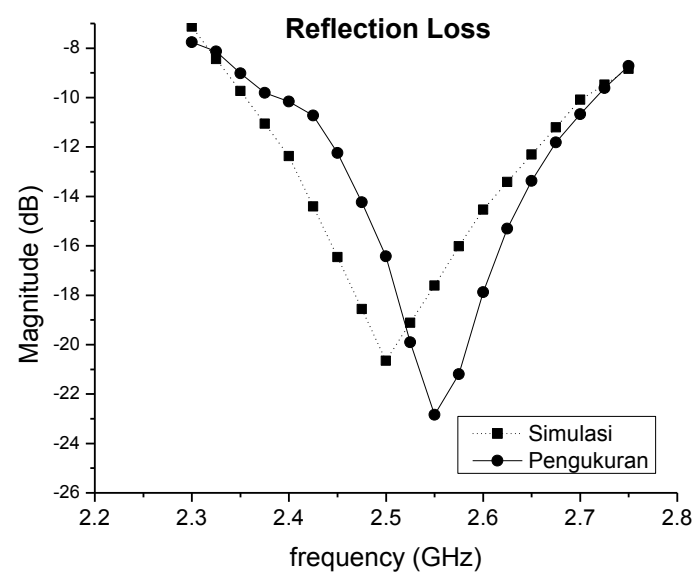

Gambar 4. Perbandingan reflection loss simulasi dengan pengukuran

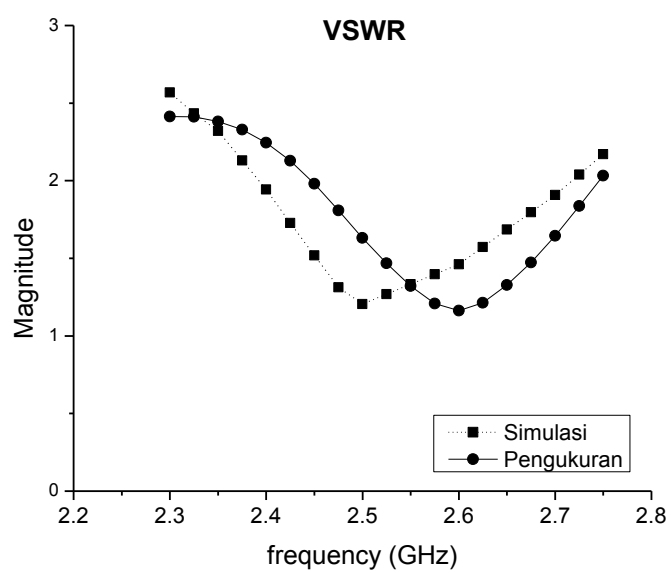

Gambar 5. Perbandingan VSWR simulasi dengan pengukuran 
Sedangkan pada Gambar 6 memperlihatkan perbandingan antara hasil simulasi dan pengukuran untuk isolation loss .

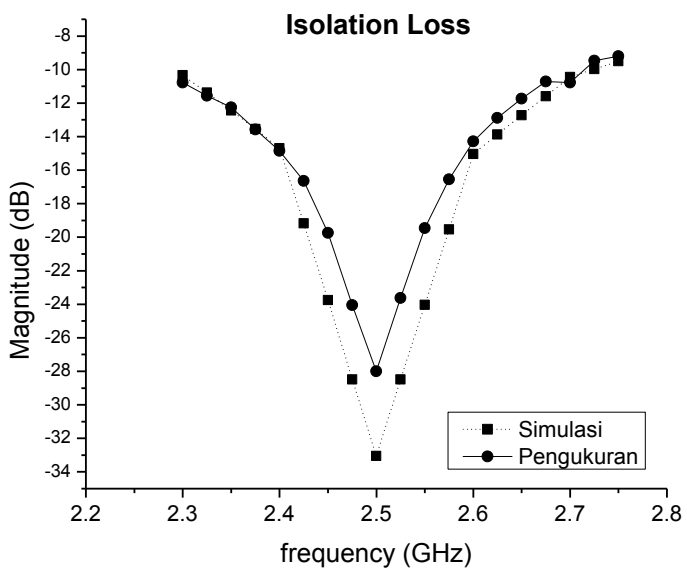

Gambar 6. Perbandingan Isolation Loss simulasi dengan pengukuran

Pada Gambar 4 dan 5 terlihat walaupun terdapat pergeseran pada kurva yang dibentuk oleh data-data hasil pengukuran, namun masih menunjukkan bentuk yang mendekati bentuk kurva dari data-data hasil simulasi. Dari kedua gambar tersebut, bandwidth yang dicapai oleh masing-masing hasil tidak menunjukkan adanya perbedaan yang signifikan

Sebaliknya pada Gambar 6 terlihat bentuk kedua kurva relatif sama dengan perbedaan magnitude dari parameter isolation loss. Perbedaan ini terjadi karena beberapa hal antara lain proses solder yang kurang rapi dan homogenitas nilai konstanta dielektrik yang tidak terdistribusi dengan merata pada substrat FR4 yang digunakan.

Perbandingan nilai parameter dari kedua hasil, baik dari simulasi maupun dari pengukuran pada frekuensi $2.45 \mathrm{GHz}$ dinyatakan dalam Tabel 1.

Pada Tabel 1, nilai magnitude coupling yang diperoleh untuk kedua hasil menunjukkan adanya perbedaan yg relatif kecil. Demikian juga dengan phase coupling masing-masing hasil masing dalam kisaran toleransi [12].

Nilai-nilai yang diperoleh dari hasil pengukuran untuk coupler ini masih dalam toleransi yang dipersyaratkan [13]. Sehingga dapat dikatakan bahwa coupler hasil fabrikasi telah bekerja cukup baik.
Tabel 1. Perbandingan Parameter hasil simulasi dan pengukuran untuk hybrid coupler pada frekuensi $2.45 \mathrm{GHz}$

\begin{tabular}{|c|c|c|}
\hline Parameter & Simulasi & Pengukuran \\
\hline Reflection Loss & $-18,27 \mathrm{~dB}$ & $-22.87 \mathrm{~dB}$ \\
\hline Isolation Loss & $-24.04 \mathrm{~dB}$ & $-19.45 \mathrm{~dB}$ \\
\hline Phase Coupling & $91.33^{\circ}$ & $-94.4^{\circ}$ \\
\hline Magnitude Coupling & -4.443 & -5.848 \\
\hline $\begin{array}{c}\text { Bandwidth pada } \\
\text { VSWR } \leqslant 2\end{array}$ & $\begin{array}{c}12.27 \% \\
(313 \mathrm{MHz})\end{array}$ & $\begin{array}{c}11.56 \% \\
(295 \mathrm{MHz})\end{array}$ \\
\hline
\end{tabular}

\section{KESIMPULAN}

Rancangan hybrid coupler dengan substrat FR4, yang bekerja pada frekuensi $2.45 \mathrm{GHz}$ berhasil dirancang bangun. Hasil pengukuran hybrid coupler tersebut menunjukkan parameter sebagai berikut, reflection loss $=-22,87 \mathrm{~dB}$, isolation loss $=-19.45 \mathrm{~dB}$ dengan phase coupling $-94.4^{\circ}$. Nilai dari reflection loss dan isolation loss berada pada nilai $\leq-10 \mathrm{~dB}$. Nilai phase coupling sebesar $-94.4^{\circ}$ masih dalam batas toleransi, sehingga kinerja coupler hasil rancangan memenuhi persyaratan yang ditetapkan

\section{UCAPAN TERIMA KASIH}

Penelitian didanai dalam kegiatan penelitian dosen Fakultas Teknik dana PNBP Universitas Andalas No. 010/UN.16.09.D/PL/2016

\section{DAFTAR PUSTAKA}

[1] Winter J. H. "Smart antennas for wireless systems", IEEE Personal Communications, Vol. 1, 23-27 (1998)

[2] Fakoukis, F.E., S. G. Diamantis, A.P. Orfanides, and G.A. Kyriacou, Development of an adaptive and a switched beam smart antenna system for wireless communications", Journal of Electromagnetic Waves and Applications,Vol. 20, No. 3, 399-408 (2006)

[3] Ho, M. J., G. L. Stuber, and M. Austin, "Performance of switched beam smart antennas for cellular radio systems," 
IEEE Trans. Veh. Technol., Vol. 47, No. 1, 10-19, (1998)

[4] Pozar,D.M., "Microwave Engineering", $2^{\text {nd }}$ ed, John Wiley \& Sons,. (1998)

[5] Mourad Nedil, Tayeb A Denidni,and Larbi Talbi,"Novel Butler Matrix using CPW Multilayer Technology", IEEE Transactions on Microwave Theory and Techniques, vol. 54, No. 1 (2006)

[6] Siti Rohaini Ahmad and Fauziahanim Che Seman, "4-Port Butler Matrix for Switched Multibeam Antenna Array", Asia-Pacific Conference on Applied Electromagnetic Proceedings, December 20-21, 2005

[7] Lamine M. Abdelghani, Tayeb. A. Denidni and Mourad Nedil, "Ultrabroadband 4x4 Compact Butler Matrix using Multilayer Directional Couplers and Phase Shifters", Microwave Symposium Digest IEEE MTT, 2012-S International, 2012.

[8] Cho, Jeong Hoon, Hee Yong Hwang and Sang Won Yun, A Design Of Wideband 3 $d B$ Coupler With $N$ Section Microstrip Tandem Structure, IEEE Microwave and Wireless Components Letters, Vol. 15, No.2 (2005)

[9] Liao,S.S., P.T.Sun, N.C.Chin, and J.T.Peng,, "A Novel Compact Size
Branch Line Coupler", IEEE Microwave and Wireless Component Letters, Vo. 15, No. 9 (2005)

[10] Sun, K.O., S.J. Ho., C.C.Yen and D.V.D. Weide, "A Compact Branch Line Coupler Using Discontinuous Microstrip Lines", IEEE Microwave and Wireless Component Letters, Vo. 15, No. 8 ( 2005)

[11] Chao Gai, Yong-Chang Jiao and Yu-Long Zhao, "Compact Dual-band Branch Line coupler with dual transmission lines", IEEE Microwave and Wireless Components Letters, Vol26, No.5 (2016)

[12] Indie Bahl and Prakash Bhartia, "Microwave Solid State Circuit Design", $2^{\text {nd }}$ ed, John Wiley and Sons (2003)

[13] Young-Hoon Chun and Jia-Sheng Hong, "Compact Wide-band Branch Line Hybrids", IEEE Transactions on Microwave Theory (2006)

\section{Biodata Penulis}

Rudy Fernandez, Dosen di Jurusan Teknik Elektro Fakultas Teknik Universitas Andalas sejak tahun 1999. Menyelesaikan pendidikan Sarjana pada tahun 1997 dan pendidikan Magister Teknik pada tahun 2010 di Universitas Indonesia. Bidang penelitian difokuskan pada antenna dan komponen microwave. 